\title{
Parenting Among Mothers With a Serious Mental Illness
}

\author{
Daphna Oyserman, Ph.D., Carol T. Mowbray, Ph.D., Paula Allen Meares, Ph.D., \\ Kirsten B. Firminger, B.A.
}

\begin{abstract}
In the past few decades, deinstitutionalization and community-based rehabilitation and support programs have increased the likelihood that women with serious mental disorders will be parents and will raise their children. This review describes what is known about the parenting of these women, focusing on diagnosis, child characteristics, and other contextual effects.
\end{abstract}

People with severe mental illness share the universal aspirations to form intimate relationships and have children. -Caton, Cournos, Felix, \& Wyatt. (1998, p. 86)

W armth, nurturance, and provision of developmentally appropriate and consistent supervision, structure, and autonomy are the universal hallmarks of good parenting, from infancy through adolescence. Yet, the specific challenges and focal issues of parenting are closely linked to the particulars of the child's developmental phase, the sociocultural context within which parenting is embedded, and attributes of the parents, including their mental health. The current review focuses on parenting among North American mothers with a long-term, serious mental illness-unipolar or bipolar affective disorder or schizophrenia (Dennis, Buckner, Lipton, \& Levine, 1991; Gonzales, Kelly, Mowbray, Hays, \& Snowden, 1991).

Understanding the parenting process among these mothers is important because a sizable number of mothers experience a serious mental illness either before or after childbirth, with risk of onset remaining elevated during the early years of parenting. Risk of serious mental illness (SMI) is separable from simple postpartum depression, which itself affects $5 \%-8.8 \%$ of women who give birth (Richards, 1990). Context of parenting and maternal mental health are inextricably linked. Being a mother of young children (under five years of age) increases risk of serious psychiatric symptoms such as anxiety and depression (Romans-Clarkson, Walton, Herbison, \& Mullen, 1988) and psychiatric disorders are more likely when mothers are stressed and caring for multiple, younger children (Puckering, 1989).

To the extent that problematic parenting at earlier developmental phases increases risk of problems in later developmental phases, risk due to maternal SMI may be cumulative. Further, because SMI is by nature episodic, with episodes lasting up to two years, children of parents with SMI are likely to experience more than one episode of parental mental illness influencing more than one developmental phase (Hammen, 1997). Maternal SMI is clearly a risk factor for children, who are at increased risk of being placed in alternative settings such as foster care (Oyserman, Benbenishty, $\&$ Ben Rabi, 1992) and of exhibiting behavior problems (Ghodsian, Zajicek, \& Wolkind, 1984). In their lifetime, $32 \%-56 \%$ of children of parents with SMI (schizophrenia or affective disorder) will themselves have a DSM diagnosable disorder ( $\mathrm{Am}$ -

A revised version of a paper submitted to the Journal in June 1999. This work was supported in part by NIMH grants 5R01MH5432105, 1R01MH5749501A1 to the first and second authors, and a W.T. Grant Faculty Scholar Award to the first author. Authors are at the Institute for Social Research, University of Michigan, Ann Arbor. 
minger et al., 1999; Rieder, 1973; Waters \& Marchenko-Bouer, 1980), with frequency depending on the diagnostic method, the parents' diagnoses, and the length of follow-up. Moreover, as summarized by Rutter, Silberg, O'Connor, and Simonoff (1999) the heritability estimate of bipolar disorder is $80 \%$; for depression, it is $34 \%-48 \%$; and for schizophrenia, it is $75 \%$.

Since appropriate parenting is importantly linked to the developmental phase of the child, as well as the particular sociocultural context in which it occurs, the risk the child experiences due to maternal mental illness is likely contingent on the interplay among onset of illness or timing of episodes, child's developmental phase, and the sociocultural context in which parenting takes place. The interaction among these factors may be complex. Mothers with SMI may have difficulty dealing with some but not all developmental phases in their children's lives, specific maternal diagnosis may interact with children's temperament and characteristics, and some diagnoses may be more risk-inducing in some cultural contexts than others (Gelfand \& Teti, 1990). Finally, ethnic and racial groups differ in their likelihood of diagnosis for depression and schizophrenia (Garb, 1997; Ruttenberg, Finello, \& Cordeiro, 1997), an effect that is as yet poorly understood. Therefore, the current review examines parenting during each phase of childhood (infancy, preschool, primary school, adolescence) separately, attempts to look at both the influence of diagnosis and the developmental needs of the child, and explores what is known about the interplay between child temperament and characteristics and maternal diagnosis. Where possible, we examine what is known about parenting for mothers who vary in their race, ethnicity, and socioeconomic status, in an effort to contextualize our understanding of the processes by which risk unfolds.

The review focuses on mothers with a mental illness, rather than parents with a mental illness, for several reasons. First, while relatively little research in this area is available, a recent literature review suggested that parenting by a mother with SMl is more likely than parenting by a father with SMI (Nicholson, Nason, Calabresi, \& Yando, 1999). In their own research on the caseload of a large urban community mental health center, Nicholson et al. found twice as many women who were known to be mothers than men who were known to be fathers. In addition, even though they are at higher risk of lifetime onset of mental illness, women with SMI are likely to fare better over time than men, but also experience high rates of pregnancy-planned or unplanned (Mowbray, Oyserman, Zemenchuk, \& Ross, 1995). Further, women with SMI are more likely to marry than are their male counterparts (Mowbray, Oyserman, Lutz, \& Purnell, 1996; Mowbray et al., 1995). Lastly, later onset of mental illnesses (other than depression) for women means that women are more likely to have the opportunity to become parents prior to the onset of SMI (Kessler, 1997). That said, when fathers are at home during childhood, the effect of their depression or other mental illness on their parenting may be similar to or different from the effects of mental illness for mothers (Jacob \& Johnson, 1997).

\section{MOTHERHOOD IN CONTEXT}

Through midlife, parenting issues are often intertwined with other stresses that themselves are likely to affect parenting adversely (Cohler, Stott, \& Musick, 1996; Stott, Musick, Clark, \& Cohler, 1983; Stott et al., 1984). A recent review of pregnancy and the postpartum period for North American mothers with SMI highlighted the stresses that both precede and co-occur with episodes of mental illness, and that continue after the episode resolves (Mowbray et al., 1995). Women with SMI have a greater number of children and begin their childbearing early, and these women are at heightened risk both of poverty and of raising their children as single parents. Marital and family strife and victimization are likely, adding to the difficulties that these mothers and their children experience (Belle, 1990; Downey \& Coyne, 1990; Olson \& Banyard, 1993).

There is some evidence that parenting can have positive and motivating effects for mothers with SMI. These women have identified motherhood as a central force keeping them involved with treatment, a key outlet for expression of feelings of care and concern, and a valued, normative social role (Mowbray, Oyserman, \& Ross, 1995; Oyserman, Bybee, Mowbray, \& Khang, 2000; Perkins, 1992). In these and other qualitative studies, women with SMI articulated the significance of having children, as well as their struggles to maintain or obtain custody and to achieve normal lives for themselves and their children (Nicholson, Sweeney \& Geller, 1998a; Sands, 1995; Schwab, Clark, \& Drake, 1991). 
It seems plausible that motherhood would be a positive and central part of women's lives, even if they have a serious mental illness. Nurturance and generativity (Erikson, 1968), as exemplified in parenting, are arguably the central tasks of adulthood. Parenting is a major social role, a normative sign of adult status, and an important developmental task (Belle, 1982; Cohler \& Musick, 1983; Gizynski, 1985; Luster \& Okagaki, 1993). Given its normative, social, and developmental status, parenting is likely to be central to one's sense of self. Successes in this domain will therefore provide the self with a sense of worth and competence, while setbacks may be particularly stressinducing, providing the basis for a variety of negative self-images (Markus \& Cross, 1990; Stott et al., 1984).

However, mothers' wishes to parent well may be thwarted by difficulties due to specific aspects of mental illness (a main effect), the interplay between the child's needs and the limitations on the mother's capacities to meet these needs due to her mental illness, or the interplay between other contextual and clinical features (interaction effects). Therefore, it is critical that evidence for problematic parenting be assessed in terms of the mother's clinical status and context as well as the age and other characteristics of the children. The current review attempts to do just that.

\section{REVIEW OF PARENTING STUDIES Overview of Method}

To reduce variability in diagnostic technique and criteria, and to insure that results described women with access to community-based care, this review is confined to English-language research published since 1980. Studies were obtained via searches of both Medline and Psych Abstracts online from January 1, 1980, to January 1, 1999, using the following key words:

maternal mental illness, parenting, child rearing, depression, mother-child relations, schizophrenia, bipolar, preschool/ school-age children, adolescence, psychiatric symptoms, affective disorders, infants, mental or psychological disorders.

To organize this review, we focused first on research documenting differences in parenting due to diagnostic differences-main effects of diagnosis-and then on research describing contextual effects.

The vast majority of this work addresses parenting and $\mathrm{SMI}$ as defined, perceived, and reacted to within an American context; the few non-U.S. studies included here are explicitly noted. Every attempt was made to include all studies describing women with SMI. Studies using a research protocol such as the Beck Depression Inventory to assess symptoms of depression in an otherwise normal community sample were excluded since these are not typically measures of SMI. Finally, studies of women with postpartum depression only were also excluded, again because it is unclear if they meet SMI criteria. However, these criteria excluded all studies on the interplay between child characteristics and maternal SMI. Therefore, the section dealing with child characteristics includes research in which the child, but not the mother, was previously diagnosed, and maternal depression was assessed for research purposes. As a rule, studies are small in size and did not attempt to obtain random or representative samples. However, as will be seen, results form a relatively coherent picture, so that, despite limitations, the studies summarized do provide working hypotheses as to the effects of maternal SMI on parenting and the mother-child relationship (Lundy, Field, McBride, Abrams \& Carraway, 1997).

Analyzing this literature, we found that, although a variety of diagnoses are contrasted, research has typically compared women with depression to control mothers or to mothers with a single other diagnosis. For purposes of clarity, studies of mental illness generally, studies comparing diagnoses, studies taking into account other clinical characteristics, and studies describing contextual influences will be reviewed here separately, as will those on child characteristics, interpersonal factors, socioeconomic influences, and parental attitudes and beliefs. Within each section, studies are organized by age of child, since age has important consequences for the tasks of parenting. This holds true, as well, for TABLES $1 \mathrm{a}$ and $1 \mathrm{~b}$, which present maternal sample size and demographic data, including socioeconomic status (SES) and race/ethnicity (where available); maternal diagnostic categories and type of diagnostic assessment; and parenting measures used in each study. Review articles that did not present original data are discussed in the text but not presented in the tables. Similarly, studies focused on mothers with depressed symptoms that help illuminate the research on mothers with SMI are cited in the text but not the tables. Where child ages were diverse, the average reported age was used to locate a study in the table. 
Table 1a

SUMMARY OF STUDIES: MAIN EFFECTS OF DIAGNOSIS

\section{STUDY}

Ducnosed vs. Contro. Monters

Infant ( $M=0-3$ yrs)

Gross (1983)

Seifer et al. (1992)

Preschool ( $M=3-5$ yrs)

Cohler \& Musick (1983); Musick et al. (1984)

Cohler et al. (1980)

Klehr et al. (1983)

Stott et al. (1983)

Stott et al. (1984)

School-age ( $M=5-12$ yrs) \& Adolescent ( $M=13-18$ yrs)

Scherer et al. (1996)

\section{Affective Disorder}

Infant ( $M=0-3$ yrs)

Cooper et al. (1988)

Stein et al. (1991)

Cohn \& Tronick (1989)

Davenport et al., (1984)

Field (1984)

Field et al. (1989)

Field, Healy, et al. (1990)

Gaensbauer et al. (1984)

Ruttenberg et al. (1997)

Preschool ( $M=3-5$ yrs)

Cox et al. (1987)

Kochanska et al. (1987)

Radke-Yarrow et al. (1985)

14 bipolar, 42 unipolar, 12 minor depression, 31 control; mostly white

Radke-Yarrow et al. (1993) 49 unipolar, 24 bipolar, 45 control Unipolar/bipolar; middle, upper middle class, white SADS-L \& DEMOGRAPHICS assessed 20 schizophrenia, 38 depression, Scales, DSM-11 diagnosis 29 personality disorder, 36 controls; heterogeneous, matched for race/SES

24 treatment, 18 controls; mixed ethnicity, SES

47 mentally ill, 48 control; middle class

34 mentally ill, 34 control; $50 \%$ Caucasian, $50 \%$ married, high SES

65 mentally ill, 36 control; matched for mother's age \& marital status, race, SES

28 mentally ill, 30 control; majority African-American, low SES, $50 \%$ single-parent official diagnosis

49 depressed, 49 control; mostly married, middle class

Depression

GHQ, PSE

Depression

depressed;

low-SES. 7 single

CES-D

cntrl: matched on social class, race, SADS

education, family composition

12 depressed, 12 control: low-SES

Depression;

BDI, STAI

7 depressed, 9 control African American, lower SES

24 depressed, 24 control

African American, low SES

Depression:

BOI

BDI

7 bipolar, 7 control

4 mothers, 3 fathers matched for age, race, SES

27 depressed, 19 control; Hispanic with premature, very low birthweight infant

49 depressed, 27 control; South London urban working class 54 mother-child dyads, 33 control; middle-class

Bipolar disorder;

SADS

Depression;

CES-D

PSE SADS-L, GAS pression; SADS

MATERNAL DIAGNOSIS OR SYMPTOMS \& SOURCE

PARENTING DEPENDENT VARIABLES

Mental functioning not formally

Maternal sensitivity/effectiveness in mother-child interactions

262 families: analyses based on Current \& Past Psychopathology Mother-infant interactions during distant, close, caretake, feed situations

Schizophrenia, schizoaffective. bipolar w/psychotic features

Previous diagnosis of psychosis

Schizophrenia, schizoaffective, manic-depressive, depression;

Schizophrenia, character disorder, Mother-child interaction during schizoaffective/affective illness; feeding, structured task, unstruchospitalized/official diagnosis

Schizophrenic, affective illness, character disorder; formal diagnosis of psychosis

Depression;

Depressive symptoms;

Manic depression/depression

Unipolar, bipolar, \& minor de- tured play situation

Mother-child interactions during feeding, structured task, unstructured play child interactions

Maternal \& child behavior ratings

Free play, drawing exercise, puzzle-construction, \& clean-up time. Parent Perception Inventory

Mother-child interaction in structured play, strange situation Naturalistic observation, face-toface, structured social interactions Strange Situation, Block Q-Sort, home observation

Infants' ability to detect mothers' affective quality of displays $\&$ behavior in face-to-face play

Sharing \& synchrony of behavior states \& heart rate

Attentive/affective behavior-state matching \& synchrony in interactions

Free play observations, Strange Situation

Mother-infant interaction, feeding

Mother-child social interaction

Maternal success, compromise, use of power, confrontation avoidance in mother-child interactions

Attachment, modified Strange Situation

Mother-child observations of predominant affect 
Table 1a (continued)

SUMMARY OF STUDIES: MAIN EFFECTS OF DIAGNOSIS

\begin{tabular}{|c|c|c|c|}
\hline STUDY & $\begin{array}{l}\text { MATERNAL SAMPLE SIZE } \\
\text { \& DEMOGRAPHICS }\end{array}$ & $\begin{array}{l}\text { MATERNAL DIAGNOSIS OR } \\
\text { SYMPTOMS \& SOURCE }\end{array}$ & $\begin{array}{l}\text { PARENTING DEPENDENT } \\
\text { VARIABLES }\end{array}$ \\
\hline \multicolumn{4}{|l|}{ Preschool ( $M=3-5$ yrs) } \\
\hline Cox et al. (1987) & $\begin{array}{l}49 \text { depressed, } 27 \text { control; South } \\
\text { London urban working class }\end{array}$ & $\begin{array}{l}\text { Depressive symptoms; } \\
\text { PSE }\end{array}$ & Mother-child social interaction \\
\hline Kochanska et al. (1987) & $\begin{array}{l}54 \text { mother-child dyads, } 33 \text { control; } \\
\text { middle-class }\end{array}$ & $\begin{array}{l}\text { Manic depression/depression } \\
\text { SADS-L, GAS }\end{array}$ & $\begin{array}{l}\text { Maternal success, compromise, } \\
\text { use of power, confrontation avoid- } \\
\text { ance in mother-child interactions }\end{array}$ \\
\hline Radke-Yarrow et al. (1985) & $\begin{array}{l}14 \text { bipolar, } 42 \text { unipolar, } 12 \text { minor } \\
\text { depression, } 31 \text { control; most white }\end{array}$ & $\begin{array}{l}\text { Unipolar, bipolar, \& minor de- } \\
\text { pression; SADS }\end{array}$ & $\begin{array}{l}\text { Attachment, modified Strange Sit- } \\
\text { uation }\end{array}$ \\
\hline Radke-Yarrow et al. (1993) & $\begin{array}{l}49 \text { unipolar, } 24 \text { bipolar, } 45 \text { control; } \\
\text { middle/upper-middle class, white }\end{array}$ & $\begin{array}{l}\text { Unipolar/bipolar; } \\
\text { SADS-L }\end{array}$ & $\begin{array}{l}\text { Mother-child observations of pre- } \\
\text { dominant affect }\end{array}$ \\
\hline \multicolumn{4}{|l|}{ School-age ( $M=5-12$ yrs) } \\
\hline Hamilton et al. (1993) & $\begin{array}{l}16 \text { unipolar, } 13 \text { bipolar, } 24 \text { non- } \\
\text { depressed, } 11 \text { chronic physical } \\
\text { illness; primarily unmarried, up- } \\
\text { per-middle SES, } 30 \% \text { nonwhite }\end{array}$ & $\begin{array}{l}\text { Unipolar depression, bipolar dis- } \\
\text { order; SADS-L, RDC }\end{array}$ & $\begin{array}{l}\text { Mother-child conflict resolution } \\
\text { task videotaped observations }\end{array}$ \\
\hline \multicolumn{4}{|l|}{ Adolescent ( $M=13-18$ yrs) } \\
\hline Gordon et al. (1989) & $\begin{array}{l}12 \text { unipolar, } 12 \text { bipolar, } 11 \text { medi- } \\
\text { cally ill, } 23 \text { control; mostly Cau- } \\
\text { casian, middle/upper-middle } \\
\text { class, unmarried }\end{array}$ & $\begin{array}{l}\text { Unipolar, bipolar disorder } \\
\text { SADS, BDI, RDC }\end{array}$ & $\begin{array}{l}\text { Unstructured interaction task, } \\
\text { mother-child interactions, Peer In- } \\
\text { teraction Rating System }\end{array}$ \\
\hline \multicolumn{4}{|l|}{$\begin{array}{l}\text { UNIPOLAR VS. BIPOLAR DEPRES- } \\
\text { SION }\end{array}$} \\
\hline \multicolumn{4}{|l|}{ School-age (M=6-12 yrs) } \\
\hline Inoff-Germain et al. (1997) & $\begin{array}{l}10 \text { bipolar, } 27 \text { unipolar, } 4 \text { minor } \\
\text { depression, } 18 \text { control families: } \\
\text { mostly white, middle class }\end{array}$ & $\begin{array}{l}\text { Unipolar, bipolar disorder; } \\
\text { SADS-L, GAF }\end{array}$ & $\begin{array}{l}\text { Family System Test, videotaped } \\
\text { family interaction, structured/semi- } \\
\text { structured interviews, question- } \\
\text { naires, family meal, parent-child } \\
\text { interaction tasks }\end{array}$ \\
\hline Tarullo et al. (1995) & $\begin{array}{l}34 \text { unipolar, } 16 \text { bipolar, } 27 \text { non- } \\
\text { depressed; primarily middle } \\
\text { class, white }\end{array}$ & $\begin{array}{l}\text { Unipolar depression, bipolar dis- } \\
\text { order; SADS-L }\end{array}$ & $\begin{array}{l}\text { Observations of mother-child inter- } \\
\text { action, differential treatment; ma- } \\
\text { ternal report of child problems }\end{array}$ \\
\hline \multicolumn{4}{|l|}{ DEPRESSION Vs. SCHLZOPHRENIA } \\
\hline \multicolumn{4}{|l|}{ Infant $(M=0-3$ yrs $)$} \\
\hline $\begin{array}{l}\text { McNeil et al. (1983) } \\
\text { Naestund et al. (1984) } \\
\text { Naeslund et al. (1985) } \\
\text { McNeil et al. (1985); Pers- } \\
\text { son-Blennow et al. (1986) } \\
\text { Persson-Blennow, Binett } \\
\text { et al.(1988); Persson-Blen } \\
\text { now, McNeil et al.(1988) }\end{array}$ & $\begin{array}{l}88 \text { diagnosed, } 104 \text { control; sub- } \\
\text { sample of McNeil et al. (1983): } 46 \\
\text { diagnosed, } 80 \text { control; prospec- } \\
\text { tive study, southwest Sweden }\end{array}$ & $\begin{array}{l}\text { Nonendogenous psychosis, } \\
\text { affective illness, schizophrenia, } \\
\text { cycloid psychosis; RDC }\end{array}$ & $\begin{array}{l}\text { Mother-infant interactions during } \\
\text { feeding \& unstructured play situa- } \\
\text { tion }\end{array}$ \\
\hline \multicolumn{4}{|l|}{ Preschool (M=3-5 yrs) } \\
\hline $\begin{array}{l}\text { Goodman \& Brumley } \\
(1990)\end{array}$ & $\begin{array}{l}53 \text { schizophrenic, } 25 \text { depressed, } \\
23 \text { control; mostly African-Ameri- } \\
\text { can. low income, single parent }\end{array}$ & $\begin{array}{l}\text { Schizophrenia, depression; } \\
\text { DSM III }\end{array}$ & Home Scale \\
\hline Sameroff et al. (1983) & $\begin{array}{l}29 \text { schizophrenic, } 58 \text { depressed, } \\
40 \text { personality disorder, } 57 \text { control; } \\
63 \% \text { Caucasian, } 34 \% \text { African } \\
\text { American, } 3 \% \text { Puerto Rican; } \\
74 \% \text { married, mixed SES }\end{array}$ & $\begin{array}{l}\text { Schizophrenia, depression and } \\
\text { personality disorder; psychiatric } \\
\text { interview }\end{array}$ & $\begin{array}{l}\text { Home and lab observations of } \\
\text { mother-child interactions; } \\
\text { Schaefer and Bell Parental Atti- } \\
\text { tude Research Instrument }\end{array}$ \\
\hline \multicolumn{4}{|l|}{ School-age (M=6-12 yrs) } \\
\hline Rogosch et al. (1992) & $\begin{array}{l}48 \text { mothers; low SES, minority } \\
\text { sample }\end{array}$ & $\begin{array}{l}\text { Schizophrenia, schizoaffective, } \\
\text { affective disorders; DSM III clin- } \\
\text { ical interview diagnosis }\end{array}$ & $\begin{array}{l}\text { Positive involvement, negative } \\
\text { control, lax discipline; social sup- } \\
\text { port }\end{array}$ \\
\hline
\end{tabular}

Note. Studies are listed only once; for studies with results pertaining to multiple sections, listing is in the first relevant section. Studies using the same sample are cited together where possible; those with multiple age groups of children are cited by primary focus where possible. Abbreviations of measures follow, in alphabetical order: BDI-Beck Depression Inventory; CES-D-Center for Epidemiological StudiesDepression Scale; DSM-III-Diagnostic and Statistical Manual of Mental Disorder; FACES-III-Family Cohesion Scale of the Family Adaptability and Cohesion Evaluation Scales-III; GAF_-Global Assessment of Functioning Scale; GAS-Global Assessment Scale; GHQ General Health Questionnaire; MMPI-Minnesota Multiphasic Personality Inventory; NIMH DIS-National Institute of Mental Health Diagnostic Interview Schedule; OPS-O-O'Leary-Porter Scale; PRS-Parental Role Stress; PSE-Present State Examination; PSI-Parenting Stress Index; RDC-Research Diagnostic Criteria; SADS-Schedule for Affective Disorders and Schizophrenia; STAI-State-Trait Anxiety Inventory. For more detail on measures, see cited study. 


\section{SMI Mothers vs Control Mothers}

Nine of the studies reviewed compared control mothers to mothers with SMI, i.e., did not provide analyses by diagnostic category. These studies dealt primarily with parenting in the preschool years. When mentally ill and control mothers are contrasted without regard to diagnosis, the assumption is that mental illness per se, rather than the specific diagnostic category, impairs capacity for empathetic, nurturant, and appropriate parenting (Klehr, Cohler, \& Musick, 1983). However, since the research reports in this section provide no analysis by diagnostic type, their findings cannot constitute evidence for or against this assumption. Further, while all of these studies reported that subjects and controls were matched on SES or race, only one of them provided this information about sample mothers and none of the studies took race or SES into account in their analyses; most participants appear to be white and middle to high SES.

Infants. Two studies compared diagnosed and nondiagnosed mothers of infants. In a small clinical sample, Gross (1983) found no main effect of being mentally ill, but did find differences in infant outcomes related to parenting style (as described below, under context of parenting). In a second, larger study of parenting, with relatively few mothers who could be diagnosed as severely mentally ill, Seifer, Sameroff, Anagnostopolou, and Elias (1992) found that when infants were four months old and again when they were 12 months old, mothers with SMI were rated as less responsive to their infants when they were close, i.e., within arms length of them. This finding presages findings of differences in mother-infant communicative synchrony described below in the literature on maternal depression.

Preschoolers. Six studies conducted by Cohler and his colleagues focused on comparisons of diagnosed and nondiagnosed mothers of preschoolers. Control and diagnosed mothers differed particularly in the context of feeding. Mothers with a mental illness were less emotionally available, less reciprocal, less involved, less positive, and more likely to view denial as a means of dealing with child-care concerns (Cohler, Gallant, Grunebaum, Weiss, \& Gamer, 1980; Cohler \& Musick, 1983; Klehr et al., 1983; Musick, Stott, Spencer, Goldman, \& Cohler, 1984; Stott et al., 1983, 1984). Compared to nondiagnosed mothers, mothers with SMI viewed establishing a reciprocal relationship with their young child as less important and differentiating their own needs from those of the child as less likely than did nondiagnosed mothers (Cohler et al., 1980). Klehr and colleagues (1983) found differences between seriously mentally ill and control mothers on five of seven interpersonal dimensions measured, even after a year-long intensive intervention. In their discussion, the authors suggested that women with SMI experience more difficulty in negotiating developmental tasks and are not able adequately to resolve issues necessary for good interpersonal relationships and happy lives.

School-aged children and adolescents. While participants in the infancy and preschool studies were mostly white and middle class, the single study with school-aged children involved primarily African-American, low-SES participants with psychotic disorder diagnoses. School-aged children of these mothers were more likely to have behavior problems as assessed by parent and teacher child behavioral reports. Diagnosed mothers were rated by outside observers as exhibiting less encouraging parenting behavior than low-SES comparison mothers. In addition, child behavior problems, as well as child self-competence ratings, were significantly predicted by maternal encouraging or negative-discouraging parenting style, controlling for psychiatric symptoms (Scherer, Melloh, Buyck, Anderson, \& Foster, 1996).

\section{Maternal Affective Disorders}

Maternal depression is the most common diagnosis in research on parents with mental illness. The 15 studies reviewed here focus on chronicity or severity of mental illness; studies of other contextual issues or parenting attitudes are reviewed later in this article. In this section, while two studies reported controlling for race and SES, only one (Ruttenberg et al., 1997) involved Hispanic lowincome mothers; two (Field, Healy, Goldstein, \& Gutherz, 1990; Field, Healy, \& Leblanc, 1989) specified inclusion of African-American, low-SES mothers; and three additional studies (Cohn \& Tronick, 1989; Cox, Puckering, Pound, \& Mills, 1987; Field, 1984) specified non-minority-group, lower-SES mothers. All examined parenting with infants, except the Cox study, which was located in London, England. Thus, again, most of our empirical knowledge about the influence of maternal depression comes from studies of white, middleclass mothers. Only studies with infants utilized more diverse samples. 
Table $1 b$

SUMMARY OF STUDIES: INTERACTION EFFECTS

\begin{tabular}{|c|c|c|}
\hline STUDY & $\begin{array}{l}\text { MATERNAL SAMPLE SIZE } \\
\text { \& DEMOGRAPHICS }\end{array}$ & $\begin{array}{l}\text { MATERNAL DIAGNOSIS OR } \\
\text { SYMPTOMS \& SOURCE }\end{array}$ \\
\hline \multicolumn{3}{|l|}{$\begin{array}{l}\text { Community Functionine, } \\
\text { Symptom SeVERITY, Chronicity }\end{array}$} \\
\hline \multicolumn{3}{|l|}{ Infant ( $M=0-3$ yrs) } \\
\hline Campbell et al. (1995) & $\begin{array}{l}61 \text { depressed, } 60 \text { control } \\
\text { married, white }\end{array}$ & $\begin{array}{l}\text { Depression; } \\
\text { SADS, RDC }\end{array}$ \\
\hline Teti el al. (1995) & $\begin{array}{l}61 \text { depressed; } 43 \text { control } \\
\text { mostly white, married }\end{array}$ & $\begin{array}{l}\text { Depression; } \\
\text { BDI }\end{array}$ \\
\hline \multicolumn{3}{|l|}{ Preschool ( $M=3-5$ yrs) } \\
\hline Frankel \& Harmon (1996) & $\begin{array}{l}30 \text { depressed, } 32 \text { control } \\
\text { mostly married, white }\end{array}$ & $\begin{array}{l}\text { Depression; } \\
\text { SADS, RDC, BDI }\end{array}$ \\
\hline \multicolumn{3}{|l|}{ School-age ( $M=6-12$ yrs) } \\
\hline Harnish et al. (1995) & $\begin{array}{l}376 \text { mothers and children } \\
\text { national cross-sectional sample }\end{array}$ & $\begin{array}{l}\text { Depression; } \\
\text { CES-D }\end{array}$ \\
\hline $\begin{array}{l}\text { Nolen-Hoeksema et al. } \\
\text { (1995) }\end{array}$ & $\begin{array}{l}40 \text { depressed, } 40 \text { control; mostly } \\
\text { white, middle-class, married }\end{array}$ & $\begin{array}{l}\text { Depression; } \\
\text { RDC, SADS, CEDS }\end{array}$ \\
\hline $\begin{array}{l}\text { Oyserman, Bybee, Mowbray, } \\
\text { \& Khang (2000); Oyser- } \\
\text { man, Bybee, Mowbray, } \\
\text { \& McFarlane (2000) }\end{array}$ & $\begin{array}{l}379 \text { mentally ill: } 43 \% \text { depressed, } \\
27 \% \text { schizophrenia-schizoaffec- } \\
\text { tive, } 19 \% \text { anxiety or adjustment } \\
\text { disorder, } 11 \% \text { bipolar; primarily } \\
\text { African-American urban mothers }\end{array}$ & $\begin{array}{l}\text { Schizophrenia-schizoaffective, } \\
\text { depression, bipolar, anxiety or } \\
\text { adjustment disorder; research } \\
\text { DIS diagnosis, symptomatology. } \\
\text { community functioning score }\end{array}$ \\
\hline
\end{tabular}

PARENTING DEPENDENT VARIABLES
Adolescent ( $M=13-18$ yrs)

Andrews et al. (1990)
59 mothers, 76 daughters British, working class
Depression:

PSE
Mother-child interactions during feeding, face-to-face, \& toy play Feeding $\&$ free play $\&$ Strange Situation observations: PSI

Early Relational Assessment Scales and Strange Situation

Mother-child interaction tasks assessed w/Interaction Rating Scale Joint puzzle task

Parental Locus of Control Scale. PSI, Block Child Rearing Practices, Parenting Involvement in Education Scale, Sensitivity to Children, Parenting Satisfaction, meaning of motherhood factor scores

Questionnaire regarding early adverse family experiences/inadequate parenting

\section{Focus on Context}

Infant ( $M=0-3$ yrs)

Gelfand et al. (1992)

Zahn-Waxler et al. (1990)

Preschool ( $M=3-5$ yrs)

Free et al. (1996)

Goodman \& Johnson (1986)

Radke-Yarrow et al. (1994)

Webster-Stratton \& Hammon (1988)

School-age ( $M=6-12$ yrs)

Goodman et al. (1994)

Hammen et al. (1987)

Hammen et al. (1991)

Hammen et al. (1990)

Hirshfeld et al. (1997)

Hops et al. (1987)

Inoff-Germain et al. (1992)

Lundy et al. (1997)

Tarullo et al. (1994)

71 depressed, 53 control; mostly white, married

22 depressed, 22 control: mostly white, married

53 mentally ill, 31 control; mostly Unipolar/bipolar; white, middle/upper-middle class SADS, GAS

trol; mostly black, low-income DSM III

52 depressed, 38 control; mostly Unipolar/bipolar; middle, upper-middle class, white SADS-L
46 depressed, 49 control

20 unipolar, 19 control white, middle class

13 unipolar, 9 bipolar, 22 nondepressed. 14 medical; mostly white, middle class

14 unipolar, 12 bipolar, 24 nondepressed, 14 medical; mostly middle, upper-middle class, white 30 mentally ill, 41 control

27 depressed, 25 control: matched on SES

15 bipolar, 22 unipolar, 24 control; mostly middle class, white

20 depressed; low-SES, mixed racial composition

31 unipolar, 22 bipolar, 30 control; mostly white, married
Depression;

BDI

Unipolar depression:

BDI

Unipolar, bipolar

Unipolar depression, bipolar disorder; SADS-L

Anxiety disorder: NIMH, DIS, SADS

Depressive symptoms: SAOS, RDC, BDI

Unipolar, bipolar; SADS-L, RDC

Depressive symptoms: CES-D

Unipolar, bipolar: RDC, SADS-L. SADS-L, BDI, short-form MMPI
Mother-infant interactions during feeding and free play, PSI

Mother-child interaction in play and structured situation

Mother's ability to interpret and communicate emotions

Role Functioning Scale

Mother-child attachment relationship observed in experimental situation and home observation Home observation w/Dyadic Parent-Child Interaction Coding Syst.

Maternal expressed attitude

Mother-child interaction behavior

Mother-child interactions. Peer Interaction Rating System

Maternal expressed emotion, 5Minute-Speech-Sample \& lab observations of behavioral inhibition

Family interaction observations of nonverbal affective behavior

Mother-child interaction with two age-adjacent children in free play and a snack

Observer ratings of 8 dimensions of mother-child interaction

Mother-child interactions 
Table $1 \mathrm{~b}$ (continued)

SUMMARY OF STUDIES: INTERACTION EFFECTS

\begin{tabular}{|c|c|c|c|}
\hline STUDY & $\begin{array}{l}\text { MATERNAL SAMPLE SIZE } \\
\text { \& DEMOGRAPHICS }\end{array}$ & $\begin{array}{l}\text { MATERNAL DIAGNOSIS OR } \\
\text { SYMPTOMS \& SOURCE }\end{array}$ & $\begin{array}{l}\text { PARENTING OEPENDENT } \\
\text { VARIABLES }\end{array}$ \\
\hline \multicolumn{4}{|l|}{ Adolescent ( $M=13-18$ yrs) } \\
\hline Davies \& Windle (1997) & $\begin{array}{l}443 \text { adolescent-mother pairs; } \\
\text { mothers primary caregivers; } \\
\text { mostly middle-class, married, } \\
\text { white }\end{array}$ & $\begin{array}{l}\text { Depression } \\
\text { CES-D }\end{array}$ & $\begin{array}{l}\text { Family discord, adolescent girts' } \\
\text { adjustment, low famity intimacy, } \\
\text { parenting impairments w/FACES- } \\
\text { III, PRS, parental coping, \& OPS }\end{array}$ \\
\hline $\begin{array}{l}\text { Tannenbaum \& Forehand } \\
\text { (1994) }\end{array}$ & $\begin{array}{l}282 \text { adolescents and parents; } \\
\text { white, middle class }\end{array}$ & $\begin{array}{l}\text { Depressive symptoms; } \\
\text { BDI }\end{array}$ & $\begin{array}{l}\text { Father-adolescent relationship as } \\
\text { a buffer for maternal depressive } \\
\text { mood measuring child's internal- } \\
\text { ing/externalizing problems }\end{array}$ \\
\hline
\end{tabular}

Parenting as the Link

Infant ( $M=0-3$ yrs)

Jameson ef al. (1997)

29 unipolar depression, 14 con- Unipolar depression;

trol;

SADS-L, RDC

Mother-infant interaction, free play,

mostly white, married

Strange Situation task

School-age ( $M=6-12$ yrs)

Conrad \& Hammen (1989) 14 unipolar depression, 12 bipolar, Unipolar depression, bipolar dis14 chronic medical disord., 24 no order; SADS-L, BDI, short-form major psych. disorder; $80 \%$ white, MMPI $12 \%$ Hispanic, $8 \%$ African-American

Jacob \& Johnson (1997) 41 maternal depression, 50 pater- Major depression; nal depression, 50 control SADS, RDC, BDI, MMPI

Radke-Yarrow et al. (1995) 39 unipolar, 24 bipolar, 32 control; Unipolar, bipolar; mostly middle/upper-middle class, SADS-L, RDC, GAS white

Teti \&. Gelfand (1991)

48 depression, 38 controls: mostly white, married

Major depression: BDI

Teti et al. (1990)

42 major depression, 10 dysthymia, 7 adjustment disorder w/depression; mostly white, married
Major depression, dysthymia, adjustment disorder with depression; BDI
Mother-child interaction task

Mother-child, father-mother-child, father-child, father-mother interaction; problem-solving discussions Mother-child interaction, Strange Situation

PSI, Maternal Self-Efficacy Scale, mother-child interaction, feeding. free play

Maternal Self-Efficacy Scale, mother-child interaction, feeding. \& free play

Note. See Table la footnote.

Infants. In a review article, Gelfand and Teti (1990) summarized the ways maternal depression and concomitant lack of maternal responsiveness can interfere with the child's attainment of developmental goals, beginning with problems in infant attachment and language. Frankel and Harmon (1996) found that depressed mothers from a community sample rated themselves more negatively as parents and felt less attached to their infants. Mothers with a depressive episode in the 19 months after childbirth were lower in maternal rapport and facilitation than were control mothers (Cooper, Campbell, Day, Kennerley, \& Bond, 1988; Stein et al., 1991). An 18-month follow-up study, comparing primarily white, middle-class control mothers to similar mothers with a bipolar disorder (who were married to men with unipolar or substance abuse diagnoses) also found evidence of problems in parenting (Davenport, ZahnWaxler, Adland, \& Mayfield, 1984). Specifically, diagnosed mothers were disorganized, inconsistent, ineffective and tense, less happy, and less ac- tive in interactions with their infants than were control mothers. The one study that did not find an effect used a small community sample of lowincome, Hispanic mothers of low-birthweight infants, half of whom received in-home prevention services; the study assessed parenting and infants at three points in time within the first 12 months of the baby's life. Thus, it is unclear if the difference is due to the Hispanic sample, the intervention, or the fact that the diagnosis was made after delivery for purposes of the research (Ruttenberg et al., 1997).

Mothers who are depressed may provide a less than optimal environment for their infants to learn social communicative skills; for example, a study of mothers with depressive symptoms suggested that their infants may be slower at learning to match happy face to happy vocalization (Lundy, Field, Cigales, \& Cuadra, 1997). Though this study was not focused on mothers with SMI, it fits a general line of research suggesting that mothers diagnosed with depression are less affectively and in- 
teractionally synchronized with their infants. Field and her colleagues have highlighted the process of interactional synchronization (Field, 1984, 1986; Field et al., 1989, 1990). Building on similar research by Tronick and his colleagues (Cohn, $\mathrm{Ma}$ tias, Tronick, Connell, \& Lyons-Ruth, 1986; Cohn \& Tronick, 1987, 1988, 1989; Tronick, 1989; Tronick \& Gianino, 1986a, 1986b) with mothers who are not seriously mentally ill, Field's research suggests that while synchronicity normally rises in the infants' third to ninth month of life, as mothers learn to attune their affect to the child, this is less likely to occur for depressed mothers. Mothers of infants aged three to 12 months were also found to engage less in positive affect-eliciting play situations and much more in negative affect-eliciting behavior, such as poking, when they had depressive symptoms.

Similarly, in a small clinical study of mothers with postpartum depression, depressed mothers were found to have interactions of shorter duration characterized by more variable maternal onset of response to infants (Zlochower \& Cohn, 1996).

All of this research suggests that the nature of the mother-infant interaction may be influenced by maternal depression. These findings parallel research in Sweden, where depressed mothers were found to talk to their infants less and received less social contact from their infants during feeding than did other mothers (Persson-Blennow, Naeslund, McNeil, \& Kaij, 1986). Only one study contrasted bipolar with control mothers, using a small sample $(N=7)$, at ages 12,15 , and 18 months (Gaensbauer, Harmon, Cytryn, \& McKnew, 1984). Whereas control infants were less likely to have insecure attachment over time, infants of mothers with a bipolar disorder were more likely to evidence insecure attachment style.

Preschool. Insecure and avoidant attachment has been found to be relatively frequent in families with major affective disorders. Insecure attachment is particularly likely when mothers have been depressed for a larger portion of the child's life, have had a more severe depressive episode, received more intensive treatment for depression, or are single parents (Radke-Yarrow, Cummings, Kuczynski, \& Chapman, 1985). When their children were preschoolers, mothers with an affective disorder were found to express more negative affect in extended observations of simulated family interactions and were less likely to achieve compromise with their children in videotaped interac- tions (Radke-Yarrow, Nottelmann, Belmont, \& Welsh, 1993; Kochanska, Kuczynski, Radke-Yarrow \& Welsh, 1987).

Converging evidence of the effect of maternal depression on parenting in the preschool years comes from a six-month prospective study of South London urban, working class mothers of two-year old children (Cox, Puckering, Pound, \& Mills, 1987; Pound, Cox, Puckering, \& Mills, 1985; Mills, Puckering, Pound, \& Cox, 1985). These mothers were less able to sustain social interactions, more likely to ignore and use a less positive tone, and more likely to disengage, give fewer explanations, and ask fewer questions than were comparison mothers. In general, depressed mothers and their children were found to engage in more physical play and affectionate touching but not to engage in sustained or "linked" verbal interchanges. It was not that depressed mothers were not warm and affectionate with their children; it was that their warmth, expressed in physical contact, was not in tune with their child's current needs.

School-aged children. In a laboratory-based, conflict resolution task, using a racially heterogeneous sample, mothers with affective disorders were more negative in their affective style (critical, intrusive, guilt-inducing statements) than control mothers, but had no more problems communicating in interactions with their 8-16-year-old $(M=12)$ children (Hamilton, Jones, \& Hammen, 1993).

Adolescence. Mother-child interactions were observed as part of a longitudinal study of mostly Caucasian, middle class, high-risk, 8-16-year-olds ( $M=$ about 13 years) and their unipolar and bipolar diagnosed mothers. It was found that mothers with unipolar depression were less positive, more critical, and showed less task-oriented behavior in a conflict discussion task with their children (Gordon, Burge, Hammen, \& Adrian, 1989).

\section{Unipolar vs Bipolar Depression}

Preschool to adolescence. None of the comparisons of unipolar and bipolar disorders involve infants. Some studies reviewed in the previous section included a comparison of mothers with unipolar depression and those with a bipolar diagnosis (Gordon et al., 1989; Hamilton et al., 1993; Kochanska et al., 1987; Tarullo, DeMulder, Ronsaville, Brown, \& Radke-Yarrow, 1995). Effects were more severe for mothers with unipolar as compared to bipolar disorder. (Additional studies, discussed below under child characteristics, show in- 
teractions of maternal unipolar vs. bipolar diagnosis with child characteristics.) A single study with school-aged children suggested higher risk for bipolar mothers; insecure and avoidant attachment was particularly frequent in children of mothers with a bipolar diagnosis; and, though interaction problems overall were evident when the mother had a unipolar depressive disorder, mothers with a bipolar disorder showed more anger in family interactions (Inoff-Germain, Nottelmann, \& RadkeYarrow, 1997).

\section{Depressed, Schizophrenic, and Control Mothers}

Relatively few studies distinguish parenting of mothers diagnosed with schizophrenia from control mothers or those diagnosed with depression. Of the four studies with North American samples, two look at preschool and two at school-aged children; all involve samples with a mixed or low SES and racially or ethnically diverse samples.

Infancy. In the past two decades, the only comparisons across these diagnoses with infants came from a large-scale, longitudinal study of women giving birth in southwestern Sweden over a 4.5year period, in which children and their mothers were followed from three days postpartum until the child was one year of age. Mothers later hospitalized with a variety of nonorganic psychoses, including schizophrenia and affective disorders, were compared to never-hospitalized mothers (McNeil et al., 1983; McNeil, Naeslund, PerssonBlennow, \& Kaij, 1985; Naeslund, Persson-Blennow, McNeil, \& Kaij, 1985; Malmquist-Larsson, 1984; Persson-Blennow et al., 1986; PerssonBlennow, Binett, \& McNeil, 1988; Persson-Blennow, McNeil, \& Blennow, 1988). In this sample, fewer differences were found when mothers were observed feeding their children than when they were observed at play with their children, although later-hospitalized and control mothers differed in both feeding and play situations. Specifically, diagnosed mothers were more uncertain about their infant's needs, provided less social contact, were less involved with their infant, and were less able to create a positive emotional climate. These differences were especially pronounced in the first six weeks postpartum, diminishing thereafter.

Specific differences were found across diagnosis in the later-hospitalized group. Mothers diagnosed with cycloid psychosis (a variety of schizoaffective diagnosis) differed most from comparison mothers, followed by those diagnosed as having schizophrenia. At the one-year assessment period, infants of these mothers were less likely to exhibit secure attachment, and more likely to exhibit deviant fear of strangers than were comparison infants. Mothers diagnosed as having an affective disorder were observed to have interactions that were at least as positive as the comparison group until the one-year assessment. At this time, these mothers were found to talk less with their infant during feeding; reciprocally, the infant showed less social contact with the mother.

Preschool. In a longitudinal study following an American sample of racially and economically diverse mothers from pregnancy through four years of age, differences in the group with schizophrenia occurred mostly in the first four months (Sameroff. Seifer, \& Barocas, 1983). In these first months, mothers with schizophrenia were less involved; however, all other significant between-group differences focused on mothers with depression, who were more anxious and less socially competent. At 30 months, these mothers reported that their infant showed less adaptive behavior. Conversely, in terms of cognitive development, the children of mothers with schizophrenia showed highest risk. In a subsequent study comparing African-American control mothers to African-American mothers with schizophrenia or depression, Goodman and Brumley (1990) found that mothers with schizophrenia had the lowest quality parenting.

School-aged children. A small clinical study of hospitalized mothers with schizophrenia or an affective disorder failed to find significant differences on self-rated maternal sensitivity by diagnosis (Rogosch, Mowbray, \& Bogat, 1992). In a largescale study of mothers with SMI receiving treatment in a metropolitan area, Oyserman, Bybee, Mowbray, and Khang (2000) found that, while diagnoses did not differentiate maternal responses, level of symptomatology and community functioning did predict maternal identity. Positive maternal identity, in turn, related to more selfreported nurturant parenting styles.

\section{Diagnoses vs Other Clinical Characteristics}

Although studies of maternal depression generally suggest that it is a clear risk factor for children (Hammen, 1997), its relative risk is difficult to determine for a number of reasons. First, as is shown in the present review (see TABLE la), research normally involves specific diagnostic comparisons between mothers with depression and one other 
group, making ranking of the relative risk of each diagnosis impossible. Second, research typically focuses on parenting within a specific child age group (e.g. 0-3 years) or does not analyze parenting by age of child. The bulk of current research contrasts depressed and control mothers (depression is studied in 14 of 23 studies with infants, 8 of 17 studies with preschoolers, 15 of 23 studies with school-age children, and all studies with adolescents). Third, the published studies we found did not analyze the possible interplay among maternal diagnosis, race, and SES. Further, when mentioned, race of participants was nearly always white, and SES nearly always middle class or higher, severely limiting generalizability of findings.

Thus, when describing the influence of maternal mental illness on parenting among infants, our knowledge base comes primarily from research on the influence of depression in white and middleclass mothers. Few studies have included systematic comparisons across the spectrum of psychiatric diagnoses, and inclusion of racial and socioeconomic factors in analyses is almost nonexistent. In addition, as will be elaborated on in the next section, only seven of the 66 articles reviewed attempted to isolate the effect of diagnosis from that of other clinical variables such as chronicity, symptom levels, and current community functioning. Further, because the seven studies that assessed these other clinical variables primarily involved maternal affective disorders, our knowledge of the effect on parenting of diagnosis, as compared to symptom severity or chronicity, is limited to depression.

Community functioning. In a sample of mothers with a unipolar or bipolar depression diagnosis and school-aged children, Inoff-Germain and colleagues (1997) found that community functioning related strongly to almost all the parenting variables assessed. Although the independent effect of functioning, controlling for the effect of diagnosis, was not presented, the authors showed that mothers who functioned better in the previous year had fewer affective problems in family interactions. In our own ongoing research with low-SES, AfricanAmerican mothers with affective and schizophrenic disorders, we also found a promotive effect of current community functioning on parenting outcome variables, with no effect of diagnosis (Oyserman, Bybee, Mowbray, \& McFarlane, 2000).

Symptom severity. Four studies described the significant influence of severity of symptoms on outcomes. In a longitudinal study of mothers with depression, severity of depression was predictive of insecure attachment when the infant was both one and two years of age (Teti, Gelfand, Messinger, \& Isabella, 1995). Women with "double depression" (unipolar episodes and dvsthymia) were less emotionally available and more negative, and had preschool-aged children who were less securely attached than did women with simple depression (Frankel \& Harmon, 1996). In a national cross-sectional sample of school-aged children, severity of depressive symptoms was inversely related to the quality of the mother-child relationship (Harnish, Dodge, \& Valente, 1995). A second largescale study of mothers with depression used a pattern-matching test of solvable puzzles to show that level of mothers' depressive symptoms correlated significantly with their negative affect and with their school-aged children's enthusiasm, persistence, and frustration on the tasks overall (Nolen-Hoeksema, Wolfson, Mumme, \& Guskin, 1995).

Chronicity. Six studies reported influence of psychiatric history on parenting in North American samples. Lifetime history (Gordon et al., 1989), number of episodes and duration of current episode (Nolen-Hoeksema et al., 1995), and portion of child's lifetime during which mother experienced depressive episodes (Radke-Yarrow et al., 1993) did not influence parenting behavior in the three studies cited. However, three other studies did find a negative impact of chronicity of mental illness on parenting. Campbell, Cohn, and Meyers (1995) found that chronicity of maternal depressive symptoms influenced mother-child interactions at two, four, and six months of age. Rogosch et al. (1992) reported that frequent recent rehospitalizations significantly predicted lower parenting sensitivity in mothers of school-aged children. Lastly, Gross (1983) found that chronicity, rather than mental illness diagnosis per se, negatively affected parental sensitivity and effectiveness. A single study with a British sample also suggests an impact of chronicity: Andrews, Brown, and Creasey (1990) found significant differences in adolescent or young adult daughters' reports of early inadequate parenting based on whether mothers had a single short episode or a chronic, recurrent psychiatric disorder.

\section{Focus on Context}

Explicating the parenting context of mothers with SMI is critical since contextual factors may 
bolster or constrain mothers' abilities to provide age- and culturally appropriate, "good enough" parenting. This section examines the literature on influences of children's ages and other characteristics, support available to the mother, and ecological maternal stresses such as poverty.

\section{Child's Age/Developmental Phase}

The child's age or developmental phase can affect maternal behavior and responsivity in a number of ways. First, traditional American theories of child development hold that maternal illness episodes during the child's first year of life and frequent separations may be quite damaging. This applies particularly to infants and younger children, since it is through interactions with their primary caregivers that their basic social skills, sense of self, and self-competence are established (Lundy, Field, Cigales et al. 1997). As children develop, mature, and become more independent, their outcomes may be shaped less by parents and more by interactions with nonfamilial adults and peers, so that weaker effects with age would result (Harris, 1995). For example, Klehr and colleagues (1983) suggested that early separations are more predictive of problems in the child's capacity for object relations and use of defense mechanisms than are specific maternal diagnostic category or chronicity of illness. Alternatively, it is possible that maternal mental illness is particularly problematic after infancy. For example, if the effects of maternal psychiatric condition and parenting problems are cumulative, then we might expect stronger relationships between maternal disorder and problematic child outcomes for older children.

Unfortunately, systematic comparisons of results across various developmental stages of childhood are rare. When tested, age effects are explored either by examining interactions between maternal psychiatric variables and children's ages or by utilizing child age as a covariate. Several of the more comprehensive investigations utilized a narrow child age range (e.g., Nolen-Hoeksema et al., 1995), and studies with a wider child age range did not test for age differences (e.g., Hamilton et al., 1993). However, Inoff-Germain et al. (1997) did report that the highest rates of behavioral problems were for younger children (average age about nine) versus older children (average age about 13), especially in the children of mothers with a bipolar disorder.

Perhaps because studying both child age and other relevant factors requires large and diverse samples, it is rarely undertaken. When possible age effects have been studied for children within a particular developmental phase, none was found in preschool (Free, Alechina, \& Zahn-Waxler, 1996; Goodman \& Brumley, 1990; Kochanska et al., 1987; Radke-Yarrow et al., 1993; Radke-Yarrow, Zahn-Waxler, Richardson, Susman, \& Martinez, 1994) or school-age samples (Hirshfeld, Biederman, Brody, Faraone, \& Rosenbaum, 1997). In addition, Tarullo et al. (1995) and Inoff-Germain et al. (1997), both having examined relationships between mother-child interactions and maternal psychiatric variables for younger versus older siblings, found no differential effects. However, maternal age, children's age, and duration of mental illness are likely to be confounded; as mothers age, so do their children and there is a parallel increase in number of years with a mental illness diagnosis. To the extent that some problematic symptomssuch as active symptoms-are associated with the onset of a mental illness, then younger children are more likely to experience parenting from a severely impaired mother. This multicausality has yet to be addressed empirically.

\section{Child/Parent Characteristics}

In addition to developmental shifts, parenting and parenting contexts interact with child characteristics and behavior recursively and in multiple ways over time to affect child outcomes (Greenberg, 1998; Patterson, 1998; Reid, 1998; Sameroff et al., 1983). Two recent studies of mothers with depressive symptoms suggest that newborns of these mothers show less orientation toward faces, less interest in them, and more "pre-cry" responses (Lundy, Field, \& Pickens, 1996) and that, at four months, these infants are rated as more vulnerable and engage in less exploratory play (Field et al., 1996), suggesting that parenting may be more difficult and less rewarding for depressed mothers of such more difficult infants.

Child gender. A few studies focus on the interplay between child gender and parenting. First, in a study of unipolar, bipolar, and control mothers (Radke-Yarrow et al., 1993), unipolar depressed mothers of daughters had more sustained bouts of negative affect, more negative affect overall, and more anxious, sad, and downcast affect than other mothers. In interactions with sons, depressed mothers were no more negative than were control mothers. Radke-Yarrow and colleagues (1993) found a significant correlation between the total 
amount of negative affect expressed by depressed mothers and their daughters. Similarly, Tarullo, DeMulder, Martinez, and Radke-Yarrow (1994) found that, among school-aged offspring of mothers with affective, especially bipolar disorder, children were less engaged in interactions with mothers and generally less happy and at ease with their mothers; mothers were more negative and critical, especially if children had behavioral problems. These findings are amplified for mother-daughter interactions and increase as daughters reach adolescence. This effect may be mediated by family functioning: Davies and Windle (1997) found that family discord mediates the effect of maternal depressive symptoms on adolescent girls' adjustment. Overall, girls may be more responsive to maternal depression, such that lower levels of maternal depression are needed to elicit caring responses from girls than they are from boys (RadkeYarrow et al., 1994).

Child behavior. two comprehensive reports studying parenting of mothers with a mental illness addressed interactive effects of mother and child variables. Utilizing data from the UCLA Family Stress Project and structural equation modeling, Hammen, Burge, and Stansbury (1990) found that child outcomes are best predicted by the interaction between maternal functioning and child behavior. Second, Cox and colleagues (1987) reported that when the children of depressed mothers showed significant behavior disturbance, mothers were less likely to connect with or follow the cues of their children.

Eight smaller, clinical studies corroborate these findings. Gelfand, Teti, and Fox (1992) found interaction between maternal depression and infant temperament, such that mothers of difficult infants reported increased parenting stress. In another study of mothers with depression, mothers' parenting problems and childhood aggression at age two predicted child externalized problems at age five (Zahn-Waxler, Iannotti, Cummings, \& Denham, 1990). School-aged children with externalizing disorders were found to have fewer interactions with and less positive affect toward their depressed mothers (Lundy et al., 1997). Mothers with an anxiety disorder were more critical of their behaviorally inhibited school-aged children (Hirshfeld et al., 1997). Mothers with a history of unipolar disorder made more self-blaming statements, but also were more likely to have school-aged children with a history of depression or anxiety (Goodman,
Adamson, Riniti, \& Cole, 1994). In a series of hierarchical regression analyses, Gordon et al. (1989) showed that mothers' chronic stress reduced the quality of maternal communication in a discussion-interaction task with adolescent children above and beyond the contribution of current symptoms. Children who viewed their mothers as having more symptoms were rated as less competent and rated their own self-worth as lower; this effect was most pronounced when mothers and their children had conflicting reports of maternal symptoms (Scherer et al., 1996). Finally, in a study of the interactions between mothers with depression and two close-in-age preschool or schoolaged siblings, mothers with bipolar depression were found to have the most negatively interacting family groups while mothers with unipolar depression were found to have a dearth of negativity compared with control families (Inoff-Germain, Nottelmann, \& Radke-Yarrow, J992).

\section{Social/Interpersonal Context}

Marital discord and social isolation are common for seriously mentally ill mothers and their children (Cox et al., 1987; Downey, \& Coyne, 1990), as are conflicts with extended family (Nicholson, Sweeney, \& Geller, 1998b) and histories of sexual abuse (Alexander \& Muenzenmaier, 1998). Moreover, once in place, marital conflict is likely to persist between episodes of depression (Puckering, 1989). Further, depressed persons tend to marry spouses with a psychiatric illness, a family history of psychopathology (Davenport et al., 1984; Merikangas \& Spiker, 1982; Wang \& Goldschmidt, 1994), or substance abuse (Davenport et al., 1984). When depressed persons have psychiatrically disturbed spouses, their own symptoms are more severe, and child symptoms (Zahn-Waxler et al., 1990) and marital and family disturbances are more likely (Puckering, 1989; Quinton, Rutter, \& Liddle, 1984).

Compared to control mothers, mothers diagnosed with depression are more likely to have adverse life experiences, particularly in the domain of close relationships (Cox et al., 1987; Downey \& Coyne, 1990; Goodman \& Johnson, 1986; Mills et al., 1985; Pound et al., 1985; Webster-Stratton \& Hammond, 1988). For mothers with a depression diagnosis, marital discord contributes to negative interactions with children (Hops et al., 1987). Maternal depression, stressful life events, and child depression are likely to interact, such that the experience of stressors might explain the temporal 
association of depressive episodes in mothers and diagnoses of depression in their children (Hammen, Burge, \& Adrian, 1991; Hammen et al., 1987). In addition, multiple hospitalizations and the chronicity of mental health problems can contribute to marital breakups and reduce paternal involvement. At least one report has suggested that this is likely when husbands give up hope of their spouse's eventual recovery and begin to fear that their children will become mentally ill like their mother (Cohler \& Musick, 1983).

Both unstable living arrangements and erratic contacts with fathers have been found to characterize families with a maternal schizophrenia diagnosis (Caton et al., 1998). Absent fathers are a risk factor, in that a positive father-adolescent relationship can act as a significant buffer for maternal depressed mood (Tannebaum \& Forehand, 1994), and better outcomes for mothers and their children are reported when the spouse or partner is supportive (Puckering, 1989). Higher levels of chronic stress, lower rates of positive life events, and single parenthood are all predictive of more negative maternal affective style (Hamilton et al., 1993). In a small sample of hospitalized mothers, social support correlated with increased self-esteem, which in turn correlated with more adaptive parenting style (Rogosch et al., 1992). Lack of social support, family discord, and marital stress have all been linked to negative outcomes for the children of mothers with SMI. However, in a small study of low-income African-American mothers, social support received in the past month did not improve parenting (Goodman \& Johnson, 1986).

\section{Economic Context}

Stresses of single parenting under conditions of poverty with concomitant social isolation and marital discord can at least partly account for the initiation or maintenance of child disorders (Ghodsian et al., 1984; Hammen et al., 1987; Sameroff et al., 1983). Mothers with less education and lower SES, whether diagnosed with a mental illness or not, may be less effective in their maternal roles. Harnish et al. (1995) found a significant relationship between mother-child interaction quality and SES for a large representative sample of children (see also, Gross, 1983). And women with SMI are at risk of chronic economic hardships (Belle, 1982; Dennis et al., 1991; Goodman \& Johnson, 1986; Sameroff et al., 1983), such as poverty and overcrowding. These factors, as well as living on an upper story in a building with no elevator and spending many days alone with one's baby, predicted child behavior problems in a longitudinal study of British-born mothers in central London, with little additional variance explained by maternal depression (Puckering, 1989).

\section{Other Contextual Variables}

Because separations from children may be particularly damaging, community-based treatment should be used to mediate the effects of stressors on mothers with SMI. For example, Free et al. (1996) reported that depressed mothers receiving treatment were better able to speak accurately with their preschool children about emotions than were depressed mothers not receiving psychotherapy. However, it is unclear to what extent women enrolled in ongoing mental health interventions typically receive any treatment that addresses, or even considers, their needs as mothers or the needs of their children. For example, $44 \%$ of psychiatric inpatient records at a private teaching hospital did not indicate whether the patient had children; when parenthood was documented, whereabouts of children were recorded in only $20 \%$ of cases, and children were contacted in only $32 \%$ of cases (DeChillo, Matorin, \& Hallahan, 1987). In the U.S., several outpatient programs supporting mothers with SMI have been reported (Cohler \& Musick, 1983; Gonzales et al., 1991; Oates, 1988; Stott et al., 1984; Tableman, 1987; Waldo, Roath, Levine, \& Freedman, 1987), but their numbers are limited (Oyserman, Mowbray, \& Zemencuk, 1994).

\section{Parenting as the Link Between}

Psychiatric Variables and Child Outcomes

A number of authors have articulated possible frameworks through which psychiatric variables (particularly depression) affect parenting and thus contribute to problem behavior in children ( $\mathrm{Gel}$ fand \& Teti, 1990; Hammen, 1991b; Puckering, 1989). For example, Hammen (199/b) suggested that depression may reduce maternal receptivity to children's cues. Lack of adequate and sensitive caregiving during infancy affects the infant's later capacity to regulate tension and experience personal integrity. This dampened capacity, in turn, results in a lifelong deficit in the child's ability to soothe tensions and manage transactions in the world, creating a sense of personal depletion and despondency (see Hammen [1997], for a more detailed review of this literature). 
Some empirical evidence supports the notion that mothers with depression are at risk of more problematic parenting styles, increasing risk for their children. Among depressed mothers of infants in a clinical sample, those who felt efficacious as parents were more competent in their observed parenting interactions than were those who did not (Teti, Gelfand, \& Pompa, 1990), and efficacy fully mediated the relationship between depression and parenting (Teti \& Gelfand, 1991). Depressed mothers of 13-29-month-old toddlers were less able to focus on and sustain interactions with their toddler than were nondepressed mothers (Jameson, Gelfand, Kulcsar, \& Teti, 1997). In a sample of depressed and nondepressed mothers of children, aged 3-8 years, who were receiving services for their behavior problems, depressed mothers reported more negative attitudes about their children (Goodman et al., 1994) and their own parenting, and more parental stress (Webster-Stratton \& Hammond, 1988). Use of affectively charged, hostile, critical, and negative statements in describing one's children has been linked to maternal history of depressive episodes (Goodman et al., 1994).

Moreover, Goodman et al. (1994) found that positive parenting moderated outcomes for children of depressed, but not of well mothers. Depressed mothers of children 3-16 years of age expressed more dysphoric and less positive parenting affect; and positive parenting reduced the likelihood that their children would respond aggressively to the mother (Hops et al., 1987). While maternal depression is a risk factor, parenting variables were found to be significant predictors of child social behavior and IQ, controlling for maternal psychiatric diagnosis (Goodman \& Brumley, 1990). Independent of diagnosis, when mothers believed in encouraging individuation, mastery, and positive interactions, their children performed better on cognitive and socioemotional measures (Cohler et al., 1980). Maternal anticipatory and respectful guidance for children two years of age predicted fewer problems for these children when they were five years old (Zahn-Woxler et al., 1990).

Mothers low in maternal effectiveness and sensitivity, whether mentally ill or not, had unrealistic expectations of their children's cognitive capacities and were unable or unwilling to allow their children to take initiative in play, requiring that children control their own interests and affect and follow maternal interests. At the same time, children of these mothers were less able to control their anger and more resistant to maternal bids for affection than were children of more sensitive and effective mothers (Gross, 1983). Maternal depression increases risk of family conflict, which in turn increases adolescent psychiatric symptoms ( $\mathrm{Da}$ vies \& Windle, 1997). Maternal depression may also reduce mothers' positivity bias: while mothers generally underestimate their child's problems, depressed mothers are accurate in reporting the behavior problems of their school-aged children (Conrad \& Hammen, 1989). The one study we found that contrasted the effects of maternal and paternal depressive symptoms concluded that maternal symptoms had a larger negative effect on overall family positivity and the positivity of parent-child interactions specifically, especially when the child was a daughter (Jacob \& Johnson, 1997).

However, even when children are able to form a secure attachment to their affectively disordered mother, the close nature of the bond may function to channel children toward affectively disordered coping styles later in life. Thus, in a longitudinal study of the interplay between security of attachment and maternal mental illness, children at age six, especially girls, who had been securely attached as infants to mothers with severe depression were more likely to display depressive symptoms themselves, while children who were insecurely attached as infants to mothers with a bipolar disorder did not display problematic levels of anxiety when they were six-year-olds (Radke-Yarrow et al., 1995).

\section{CONCLUSIONS}

This review of what is known about parenting of women with a serious mental illness suggests that detrimental effects of maternal depression emerge by the time the infant is one year of age, and that a diagnosis of depression may be useful in making predictions about some aspects of parenting behavior and about mothers' parenting style. Depressed mothers are less likely to develop the synchronized interactions with their infants that aid the child's emerging sense of competence. They are more likely to have anxiously attached toddlers, even though they maintain extensive physical contact with their children. When their children are school-aged and adolescent, mothers with depression are at risk of continued negative interactional styles. They are also more prone to hold parenting attitudes that do not result in responsive and effective parenting. 
Results are similar when general, non-diagnosisspecific comparisons are made. When contrasted with bipolar diagnosis, unipolar depression appears more detrimental. Fewer studies of schizophrenia are available, and these deal mainly with infancy and the preschool years. Mothers with schizophrenia are reported to be less involved, more uncertain, and less able to create a positive climate for their infant in the first few months of life. During the school-age years, their children are most likely to have cognitive deficits.

A few studies emphasized the importance of symptom severity, chronicity of mental illness, and level of community functioning in predicting both parenting behavior and child outcomes when mothers have depression. However, the literature makes it clear that mental illness is likely to be only a small part of the total risks mothers experience; these include family disruptions and conflicts, single-parent status, social isolation, and financial and other stresses associated with living in poverty. These difficult life circumstances are often concomitant with chronic long-term depression and potentiate and exacerbate risk. Further, very few studies focus on issues related to parenting of adolescents - a particularly glaring gap, since many mental health problems begin to emerge most sharply at this age.

While negative effects of maternal mental illness have been reported across the full spectrum from infancy through adolescence, little attention has been paid to longitudinal assessment of risk over time and developmental phases. Perhaps due to the cross-sectional nature of most research, no evidence currently exists that particular phases are more risky than others. With regard to child characteristics, some studies suggest exacerbation of negative effects for daughters and for behaviorally inhibited children. However, unanswered questions about the context of parenting and appropriate comparison groups limit generalization from the current research base.

The impact of timing or sequencing has also been neglected. Yet, it seems likely that sequencing-the ordering of onset of mental illness and childbirth or episodes of mental illness and child developmental phases-will critically color both parenting and outcomes for children. A number of authors have also proposed that episodes of mental illness during infancy are likely to undermine the mother's capacity to build positive interactions with her child. This lack of positive maternal struc- ture is said to increase risk of poor attachment and undermine children's sense of competence (Hammen, 1991a). Since context clearly matters, it may be critical to compare how mothers with similar life circumstances cope with long-term and episodic chronic physical illnesses, in order to determine the extent to which findings are specific to mental illness.

The likelihood that many mentally ill women will raise their children makes it important to draw on the current empirical literature to extrapolate appropriate assessment and intervention applications. Since women with a mental illness are likely to have children, their existence, age, and whereabouts should be one of the initial foci of assessment. When children are involved, plans should be developed for their stable care, and parenting should be bolstered by appropriate supports. In our own research (Oyserman, Bybee, Mowbray, \& McFarlane, 2000), we have found that current stresses and functioning, rather than diagnosis and provision of social supports to mothers, is particularly important in predicting positive parenting attitudes and behavior (e.g., nurturance and involvement with children's education). Careful assessment of the course of the mother's mental illness, its interplay with childbirth and child rearing, and detailed attention to the current expression of the illness may provide a road map for intervention-although the current cross-sectional research base does not offer much to build on.

Because their children are at risk of exhibiting social, emotional, and behavioral problems at home and school, the parenting challenges these mother face should be assessed and appropriate supports provided, including interventions with mothers and children. Mothers are more likely to be effective when given the opportunity to take on responsibilities (Goepfert, Webster, Pollard, \& Nelki, 1996), yet they need ongoing support in parenting to reduce the negative sequelae of past and future episodes of mental illness.

It seems reasonable to conclude that mothers' capacity to parent will be framed by their past and current experiences and life situations, and not simply by their diagnostic category. Research to date has not provided a window into the way that women's past life experiences-not only mental illness, but related stresses such as poverty, victimization, and involvement in mental health services-are incorporated into maternal identities, shaping their current focus, motivation, skills, and 
abilities. Within this general framework, it is clear that current and ongoing supports can bolster women's efforts to parent, just as current and ongoing stressors can siphon their energies and attention (Klehr et al., 1983; Stott et al., 1984). Though few studies have focused directly on mothers' maternal identity, some research suggests that mothers with a mental illness find parenting to be an important and fulfilling aspect of their lives $(\mathrm{Oy}$ serman, Bybee, Mowbray, \& Khang, 2000; Perkins, 1992). Though mothers may exhibit problematic parenting practices, they may well be interested in and amenable to interventions that facilitate increased sense of maternal self-competence and efficacy.

Future research must build on previous work by utilizing larger, more representative samples of women; following the women and their children over time; and analyzing the impact of demographic, material-economic, and social-relational support and stress factors, as well as diagnosis, on women's sense of themselves as mothers. The direct and indirect effects of these factors on parenting and outcomes for children must be studied, as well. Only by means of much larger samples can such analyses proceed; without these more costly study designs, our ability to make sense of the ways in which serious mental illness influences parenting and outcomes for children will be severely impaired. Research that addresses more adequately the current gaps in our knowledge can be the basis for interventions that provide culturally appropriate support networks for these women-not as people with mental illness, but as mothers who must guide and support their growing children and carry out the tasks of parenting in particularly difficult circumstances.

\section{References}

Alexander, M., \& Muenzenmaier, K. (1998). Trauma, addiction, and recovery. In B.L. Levin, A.K., Blanch \& A. Jennings (Eds.), Women's mental health services: $A$ public health perspective (pp. 215-239). Thousand Oaks, CA: Sage Publications.

Amminger, G.P., Pape, S., Rock, D., Roberts, S.A., Ott, S.L., Squires-Wheeler, E., Kestenbaum, C., \& ErlenmeyerKimling, L. (1999). Relationship between childhood behavioral disturbance and later schizophrenia in the New York High-Risk Project. American Journal of Psychiatry, 156, 525-530.

Andrews, B., Brown, G., \& Creasey, L. (1990). Intergenerational links between psychiatric disorders in mothers and daughters: The role of parenting experiences. The Journal of Child Psychology and Psychiatry and Allied Disciplines, 31, 1115-29.
Belle, D. (Ed) (1982). Lives in stress: Women and depression. Beverly Hills: Sage Publications.

Belle, D. (1990). Poverty and women's mental health. American Psychologist, 45, 385-389.

Campbell, S., Cohn, J., \& Meyers, T. (1995). Depression in first-time mothers: Mother infant interactions and depression chronicity. Developmental Psychology, 31, 349-357.

Caton, C., Cournos, F., Felix, A., \& Wyatt, R. (1998). Childhood experiences and current adjustment of offspring of indigent patients with schizophrenia. Psychiatric Services, 49. 86-90.

Cohler, B., Gallant, D., Grunebaum, H., Weiss, J., \& Gamer, E. (1980). Child-care attitudes and development of young children of mentally ill and well mothers. Psychological Reports, 46, 31-46.

Cohler, B., \& Musick, J. (1983). Psychopathology of parenthood: Implications for mental health of children. Infant Mental Health Journal, 4(3), 140-163.

Cohler, B., Stott, F., \& Musick, J. (1996). Distressed parents and their young children: Interventions for families at risk. In M. Goepfert (Ed.), Parental psychiatric disorder: Distressed parents and their families (pp. 107-134). Cambridge, England: Cambridge University Press.

Cohn, J.F., Matias, R., Tronick, E.Z., Connell, D., \& LyonsRuth, K. (1986). Face to face interactions of depressed mothers and their infants. New Directions for Child Development, 34, 31-45.

Cohn, J.F., \& Tronick, E.Z. (1987). Mother-infant face-to-face interaction: The sequence of dyadic states at 3,6 , and 9 months. Developmental Psychology, 23, 68-77.

Cohn, J.F., \& Tronick, E.Z. (1988). Mother-infant face-to-face interaction: Influence is bidirectional and unrelated to periodic cycles in either partner's behavior. Developmental Psychology, 24, 386-392.

Cohn, J.F., \& Tronick, E.Z. (1989). Specificity to infants' response to mothers' affective behavior. Journal of American Academy of Child and Adolescent Psychiatry, 57, 663-667.

Conrad, M., \& Hammen, C. (1989). Role of maternal depression in perceptions of child maladjustment. Journal of Consulting and Clinical Psychology, 152, 663-667.

Cooper, P., Campbell, E., Day, A., Kennerley, H., \& Bond, A. (1988). Nonpsychotic psychiatric disorder after childbirth. British Journal of Psychiatry. 152, 799-806.

Cox, A., Puckering, C., Pound, A., \& Mills, M. (1987). The impact of maternal depression in young children. Journal Child Psychiatry, 28, 917-928.

Davenport, Y., Zahn-Waxler, C., Adland, M., \& Mayfield, A. (1984). Early child-rearing practices in families with a manic-depressive parent. American Journal of Psychiatry, $141,230-235$

Davies, P., \& Windle, M. (1997). Gender-specific pathways between maternal depressive symptoms, family discord, and adolescent adjustment. Developmental Psychology. 33, $657-668$.

DeChillo, N., Matorin, S., \& Hallahan, C. (1987). Children of psychiatric patients: Rarely seen or heard. Health and Social Work, 12, 296-302.

Dennis, D., Buckner, J., Lipton, F., \& Levine, I. (1991). A decade of research and services for homeless mentally ill persons: Where do we stand? American Psychologist, 46, $1129-1138$

Downey, G., \& Coyne, J. (1990). Children of depressed parents: An integrative review. Psychological Bulletin. 108, 50-76.

Erickson, E. (1968). Identity, youth and crisis. New York: Norton.

Field, T. (1984). Early interactions between infants and their postpartum depressed mothers. Infant Behavior and Development, 7, 517-522. 
Field, T. (1986). Models for reactive and chronic depression in infancy. In E. Tronick \& T. Field (Eds.), Maternal depression and infant disturbance: New directions for child development (pp. 47-60). San Francisco: Jossey-Bass.

Field, T., Estroff, D., Yando, R., del Valle, C., Malphurs, J., \& Hart, S. (1996). "Depressed" mothers' perceptions of infant vulnerability are related to later development. Child Psychiatry and Human Development, 27, 43-53.

Field, T., Healy, B., Goldstein, S., \& Gutherz, M. (1990). Behavior-state matching and synchrony in mother-infant interactions of nondepressed versus depressed dyads. Devel opmental Psychology, 26, 7-14.

Field, T., Healy, B., \& Leblanc, W.G. (1989). Sharing and synchrony of behavior states and heart rate in nondepressed versus depressed mother-infant interactions. Infant Behavior and Development, 12, 357-376.

Frankel, K.A., \& Harmon, R.J. (1996). Depressed mothers: They don't always look as bad as they feel. Journal of the American Academy of Child and Adolescent Psychiatry, 35, 289-298.

Free, K., Alechina, I., \& Zahn-Waxler, C. (1996). Affective language between depressed mothers and their children: The potential impact of psychotherapy. Journal of the American Academy of Child \& Adolescent Psychiatry, 35, 783-790.

Gaensbauer, T., Harmon, R., Cytryn, L., \& McKnew, D. (1984). Social and affective development in infants with a manic-depressive parent. American Journal of Psychiatry, 14I, 223-229.

Garb, H. (1997). Race bias, social class bias, and gender bias in clinical judgment. Clinical Psychology: Science \& Practice, 4, 99-120.

Gelfand, D., \& Teti, D. (1990). The effects of maternal depression on children. Clinical Psychology Review, 10, 329-353.

Gelfand, D., Teti, D., \& Fox, C. (1992). Sources of parenting stress for depressed and nondepressed mothers of infants. Journal of Clinical Child Psychology, 21, 262-272.

Ghodsian, M., Zajicek, E., \& Wolkind, S. (1984). A longitudinal study of maternal depression and child behavior problems. Journal of Child Psychology and Psychiatry, 25, 91-109.

Gizynski, M. (1985). The effects of maternal depression on children. (linical Social Work Journal, 13, 103-116.

Goepfert, M., Webster, J., Pollard, J., \& Nelki, S. (1996). The assessment and prediction of parenting capacity: A community-oriented approach. In $\mathrm{M}$. Goepfert (Ed.), Parental psychiatric disorder: Distressed parents and their families (pp. 271-309). Cambridge, England: Cambridge University Press

Gonzales, L., Kelly, J., Mowbray, C., Hays, R., \& Snowden, L. (1991). Community mental health. In M. Hersen, A. Kazdin, \& A.S. Bellack (Eds.). The clinical psychology handbook. New York: Pergamon Press.

Goodman, S., Adamson, L., Riniti, J., \& Cole, S. (1994). Mothers' expressed attitudes: Associations with maternal depression and children's self-esteem and psychopathology. Journal of the American Academy of Child \& Adolescent Psychiatry, 33, 1265-1274.

Goodman, S.H., \& Brumley, H.E. (1990). Schizophrenic and depressed mothers: Relational deficits in parenting. Developmental Psychology, 26, 31-39.

Goodman, S.H., \& Johnson, M.S. (1986). Life problems, social supports, and psychological functioning of emotionally disturbed and well low-income women. Journal of Community Psychology, 14, 150-158.

Gordon, D., Burge, D., Hammen, C., \& Adrian, C. (1989). Observations of interactions of depressed women with their children. American Journal of Psychiatry. 146, 50-55.

Greenberg, M.T. (1998). Fast Track: A comprehensive model for promoting competence in childhood. Paper presented at the annual meeting of the American Psychological Association, San Francisco.

Gross, D. (1983). How some dyads "fail": A qualitative analysis with implications for nursing practice. Infant Mental Health Journal, 4, 272-286.

Hamilton, E.B., Jones, M., \& Hammen, C. (1993). Maternal interaction style in affective disordered, physically ill, and normal women. Family Process, 32(3), 329-340.

Hammen, C. (1991a). Depression runs in families : The social context of risk and resilience in children of depressed mothers. New York: Springer-Verlag.

Hammen, C. (1991b). Generation of stress in the course of unipolar depression. Journal of Abnormal Psychology, 100, 555-56!

Hammen, C. (1997). Children of depressed parents: The stress context. In S. Wolchik (Ed.), Handbook of children's coping: Linking theory and intervention (pp. 131-157). New York: Plenum Press.

Hammen, C., Burge, D. \& Adrian, C. (1991). Timing of mother and child depression in a longitudinal study of children at risk. Journal of Consulting and Clinical Psychology, 59, 341-345.

Hammen, C., Burge, D., \& Stansbury, K. (1990). Relationship of mother and child variables to child outcomes in a highrisk sample: A causal modeling analysis. Developmental Psychology, 26, 24-30.

Hammen, C., Gordon, D., Burge, D., Adrian, C., Jaenicke, C., \& Hiroto, D. (1987.) Maternal affective disorders, illness and stress: Risk for children's psychopathology. American Journal of Psychiatry, 144, 736-741.

Harnish, J., Dodge, K., \& Valente, E. (1995). Mother-child interaction quality as a partial mediator of the roles of maternal depressive symptomology and socioeconomic status in the development of child behavior problems. Child Development, 66, 739-753.

Harris, J. (1995). Where is the child's environment? A group socialization theory of development. Psychological Review, $102,458-489$.

Hirshfeld, D., Biederman, J., Brody, L., Faraone, S., \& Rosenbaum, J. (1997). Expressed emotion toward children with behavioral inhibition: Associations with maternal anxiety disorder. Journal of the American Academy of Child \& Adolescent Psychiatry, 36, 910-917.

Hops, H., Biglan., A., Sherman, L., Arthur, J., Friedman, L., \& Osteen, V. (1987). Home observations of family interactions of depressed women. Journal of Consulting \& Clinical Psychology, 55, 341-346.

Inoff-Germain, G., Nottelmann, E., \& Radke-Yarrow, M. (1992). Evaluative communications between affectively ill and well mothers and their children. Journal of Abnormal Child Psychology, 20, 189-212.

Inoff-Germain, G., Nottelmann, E., \& Radke-Yarrow, M. (1997). Relation of parental affective illness to family, dyadic, and individual functioning: An observational study of family interaction. American Journal of Orthopsychiatry. $67,433-448$

Jacob, T., \& Johnson, S. (1997) Parent-child interaction among depressed fathers and mothers: Impact on child functioning. Journal of Family Psychology, 11, 391-409.

Jameson, P., Gelfand, D., Kulcsar, E., \& Teti, D. (1997) Mother-toddler interaction patterns associated with maternal depression. Development and Psychopathology, 9. 537-550.

Kessler, R.C. (1997). The effects of stressful life events on depression. Annual Review of Psychology, 48, 191-214.

Klehr, K.B., Cohler, B.J., \& Musick, J.S. (1983). Character and behavior in the mentally ill and well mother. Infant Mental Health Journal, 4, 250-270. 
Kochanska, G., Kuczynski, L., Radke-Yarrow, M., \& Welsh, J. (1987). Resolutions of control episodes between well and affectively ill mothers and their young children. Journal of Abnormal Child Psychology, 15, 441-456.

Lundy, B., Field, T., Cigales, M., \& Cuadra, A. (1997). Vocal and facial expression matching in infants of mothers with depressive symptoms. Infant Mental Health Journal, 18, 265-273.

Lundy, B., Field, T., McBride, C., Abrams, S., \& Carraway, K. (1997). Child psychiatric patients' interactions with their mothers. Child Psychiatry \& Human Development, 27. $231-40$.

Lundy, B., Field, T., \& Pickens, J. (1996). Newborns of mothers with depressive symptoms are less expressive. Infant Behavior and Development, 19, 419-424.

Luster, T., \& Okagaki, L. (Eds.) (1993). Parenting: An ecological perspective. Hillsdale, $\mathrm{NJ}$ : Lawrence Erlbaum.

Markus, H., \& Cross, S. (1990). The interpersonal self. In L. Pervin (Ed.), Handbook of personality: Theory and research (pp. 576-608). New York: Guilford Press.

McNeil, T., Kaij, L., Malmquist-Larsson, A., Naeslund, B., Persson-Blennow, I., McNeil, N., \& Blennow, G. (1983) Offspring of women with nonorganic psychoses. Acta Psychiatrica Scandinavica, 68, 234-250.

McNeil, T., Naeslund, B., Persson-Blennow, I., \& Kaij, L. (1985). Offspring of women with nonorganic psychosis Mother-infant interaction at three-and-a-half and six months of age. Acta Psychiatrica Scandinavica, 71, 551-558.

Merikangas, K., \& Spiker, D. (1982). Assortative mating among in-patients with primary affective disorder. Psychological Medicine, 12, 753-764.

Mills, M., Puckering, C., Pound, A., \& Cox, A. (1985). What is it about depressed mothers that influence their children's functioning? In J. E. Stevenson (Ed,), Recent research in developmental psychopathology (pp. 11-17). Oxford: Pergamon Press.

Mowbray, C.T., Oyserman, D., Lutz, C., \& Pumell, R. (1996) Women: The ignored majority. In L. Spaniol (Ed.), Psychological and Social Aspects of Psychiatric Disability (pp. 171-194). Boston, MA: Center for Psychiatric Rehabilitation, Sargent College of Allied Health Professions, Boston University

Mowbray, C.T., Oyserman, D., \& Ross, S. (1995). Parenting and the significance of children for women with a serious mental illness. Journal of Mental Health Administration, 22, 189-200.

Mowbray, C.T., Oyserman, D., Zemencuk, J., \& Ross, S. (1995). Motherhood for women with serious mental illness: Pregnancy, childbirth and the postpartum period. American Journal of Orthopsychiatry, 65, 21-38.

Musick, J., Stott, F., Spencer, K., Goldman, J., \& Cohler, B. (1984). The capacity for "enabling" in mentally ill mothers. Zero 10 Three, 4, 1-6.

Naeslund, B., Persson-Blennow, I., McNeil T., \& Kaij, L. (1985). Offspring of women with nonorganic psychosis: Mother-infant interaction at three and six weeks of age. Acta Psychiatrica Scandinavica, 71, $441-450$.

Naeslund, B., Persson-Blennow, I., McNeil T., Kaij, L., \& Malmquist-Larsson, A. (1984). Offspring of women with nonorganic psychosis: Infant attachment to the mother at one year of age. Acta Psychiatrica Scandinavica, 69, 231-241.

Nicholson, J., Nason, M., Calabresi, A., \& Yando, R. (1999). Fathers with severe mental illness. American Journal of Orthopsychiatry, 69, 134-141.

Nicholson, J., Sweeney, E.M., \& Geller, J.L. (1998a). Mothers with mental illness: 1 . The competing demands of parenting and living with mental illness. Psychiatric Services, 49, $635-642$
Nicholson, J., Sweeney, E.M., \& Geller, J.L. (1998b). Mothers with mental illness: II. Family relationships and the context of parenting. Psychiatric Services, 49, 643-649.

Nolen-Hoeksema, S., Wolfson, A., Mumme, D., \& Guskin, K. (1995). Helplessness in children of depressed and nondepressed mothers. Developmental Psychology, 31, 377-87.

Oates, M. (1989). Management of major mental illness in pregnancy and the puerperium. Bailliere's Clinical Obstetrics and Gynaecology, 3, 905-920.

Olson, S., \& Banyard, V. (1993). "Stop the world so I can get off for a while.": Sources of daily stress in the lives of lowincome single mothers of young children. Family Relations. $42,50-56$

Oyserman, D., Benbenishty, R., \& Ben Rabi, D. (1992). Characteristics of children and their families at entry into foster care. Psychiatry and Human Development, 22, 199-211.

Oyserman, D., Bybee, D., Mowbray, C.T., \& Khang, S. (2000). The meaning of motherhood for women with mental illness. Unpublished manuscript, University of Michigan, Ann Arbor.

Oyserman, D., Bybee, D., Mowbray, C.T., \& McFarlane, P. (2000). Support helps: Effects of community functioning and social support on parenting of African American mothers with a serious mental illness. Unpublished manuscript, University of Michigan, Ann Arbor.

Oyserman, D., Mowbray, C.T., \& Zemencuk J. K. (1994). Resources and supports for mothers with a severe mental illness. Health and Social Work, 19, 132-142.

Patterson, G.L. (1998). Growth in new forms of antisocial behavior: On becoming a system. Paper presented at the annual meeting of the American Psychological Association, San Francisco.

Perkins, R. (1992). Catherine is having a baby. Feminism and Psychology, 2, 110-112.

Persson-Blennow, I., Binett, B., \& McNeil T.F. (1988). Offspring of women with nonorganic psychosis: Antecedents of anxious attachment to the mother at one year of age Acta Psychiatrica Scandinavia 78, 66-71.

Persson-Blennow, I., McNeil, T.F., \& Blennow, G. (1988). Temperament in children delivered by vacuum extraction. American Journal of Orthopsychiatry. 58, 304-309.

Persson-Blennow, I., Naeslund, B., McNeil T.F., \& Kaij, L. (1986). Offspring of women with nonorganic psychosis: Mother-infant interaction at one year of age. Acta Psychiatrica Scandinavia, 73, 207-213.

Pound, A., Cox, A., Puckering, C., \& Mills, M. (1985). The impact of maternal depression on young children. In J. E. Stevenson (Ed.), Recent research in developmental psy. chopathology. Oxford, England: Pergamon Press.

Puckering, C. (1989). Annotation: Maternal depression. The Journal of Child Psychology \& Allied Disciplines, 30, 807-17.

Quinton, D., Rutter, M., \& Liddle, C. (1984). Institutional rearing, parenting difficulties and marital support. Psychological Medicine, 14, 107-124.

Radke-Yarrow, M., Cummings, E., Kuczynski, L., \& Chapman, M. (1985). Pattems of attachment in two and three year olds in normal families and families with parental depression. Psychological Bulletin, 1/2, 485-499.

Radke-Yarrow, M., McCann, K., DeMulder, E., Belmont, B., Martinez, P., \& Richardson, D. (1995). Attachment in the context of high-risk conditions. Development and Psychopathology, 7, 247-265.

Radke-Yarrow, M., Nottelmann, E., Belmont, B., \& Welsh, J.D. (1993). Affective interactions of depressed and nondepressed mothers and their children. Journal of Abnormal Child Psychology, 21, 683-695.

Radke-Yarrow, M., Zahn-Waxler, C., Richardson, D.T., Susman, A., \& Martinez, P. (1994). Caring behavior in children 
of clinically depressed and well mothers. Child Development, 65, 1405-1414.

Reid, J.B. (1998). Proximal and distal impacts of a conduct problem prevention intervention. Paper presented at the annual meeting of the American Psychological Association, San Francisco.

Richards, J.P. (1990). Postnatal depression: A review of recent literature. British Journal of General Practice, 40, $472-476$.

Rieder, R.O. (1973). The offspring of schizophrenic parents: A review. The Journal of Nervous and Mental Disease, 157, 179-190.

Rogosch, F.A., Mowbray, C.T., \& Bogat, G.A. (1992). Determinants of parenting attitudes in mothers with severe psychopathology. Development and Psychopathology, 4, 469-487.

Romans-Clarkson, S., Walton, V., Herbison, G., \& Multen, P. (1988). Marriage, motherhood and psychiatric morbidity in New Zealand. Psychological Medicine, 18, 983-990.

Ruttenberg, W., Finello, K., \& Cordeiro, A (1997). Interactions between depressed and nondepressed Latina mothers and their premature infants. Infant Mental Health Journal, 18, 364-377.

Rutter, M., Silberg, J., O'Connor, T., \& Simonoff, E. (1999). Genetics and child psychiatry: II. Empirical research findings. Journal of Child Psychology and Psychiatry, 40, 19-55

Sameroff, A.J., Seifer, R., \& Barocas, R. (1983). Impact of parental psychopathology: Diagnosis, severity, or social status effects? Infant Mental Health Journal, 4, 236-249.

Sands, R.G. (1995). The parenting experience of low-income single women with serious mental disorders. Families in Society, 76, 86-96.

Scherer, D., Melloh, T., Buyck, D., Anderson, C., \& Foster, A. (1996). Relation between children's perception of matemal mental illness and children's psychological adjustment. Journal of Clinical Child Psychology, 25(2), 156-169

Schwab, B., Clark, R.E., \& Drake, R.E. (1991). An ethnographic note on clients as parents. Psychosocial Rehabilitation Journal, 15(2), 95-99.

Seifer, R., Sameroff, A., Anagnostopolou, R., \& Elias, P. (1992). Mother-infant interaction during the first year; Effects of situation, maternal mental illness, and demographic factors. Infant Behavior and Development, 15, 405-426.

Stein, A., Gath, D., Bucher, J., Bond, A., Day A., \& Cooper P. (1991). The relationship between post-natal depression and mother-child interaction. British Journal of Psychiatry, $158,46-52$.

Stott, F.M., Musick, J.S., Clark, R., \& Cohler, B.J. (1983). Developmental pattems in the infants and young children of mentally ill mothers. Infant Mental Health Journal, 4, 217-234

Stott, F.M., Musick, J.S., Cohler, B.J., Spencer, K.K., Goldman, J., Clark, R., \& Dincin, J. (1984). Intervention for the severely disturbed mother. In J. Musick \& B. Cohler (Eds.), Intervention Among Psychiatrically Impaired Parents and Their Young Children (pp. 7-32). San Francisco: JosseyBass.
Tableman, B. (1987). Stress Management Training: An approach to the prevention of depression in low-income populations. In R. Munoz (Ed.), Depression prevention: Research directions (pp 171-184). Washington, DC: Hemisphere Publishing.

Tannenbaum, L., \& Forehand, R. (1994). Matemat depressive mood: The role of the father in preventing adolescent problem behaviors. Behavior Research \& Therapy, 32, 321-325.

Tarullo, L., DeMulder, E., Martinez, P., \& Radke-Yarrow, M. (1994). Dialogues with preadolescents and adolescents: Mother-child interaction patterns in affectively ill and well dyads. Journal of Abnormal Child Psychology, 22, 33-51.

Tarullo, L., DeMulder, E., Ronsaville, D., Brown, E., \& Radke-Yarrow, M. (1995). Maternal depression and maternal treatment of siblings as predictors of child psychopathology. Developmental Psychology, 3l(3), 395-405.

Teti, D., \& Gelfand, D. (1991). Behavioral competence among mothers of infants in the first year: The mediational role of maternal self-efficacy. Child Development, 62, 918-929.

Teti, D., Gelfand, D., Isabella, R., \& Messinger, D. (1995). Maternal depression \& the quality of early attachment: An examination of infant preschoolers and their mothers. $D e$ velopmental Psychology, 31, 364-76.

Teti, D., Gelfand, D., \& Pompa, J. (1990). Depressed mothers' behavioral competence with their infants: Demographic and psychosocial correlates. Development and Psychopathology, 2, 259-270

Tronick, E. (1989). Emotions and emotional communication in infants. American Psychologist, 44, 112-119.

Tronick, E.Z., \& Gianino, A.F. (1986a). Interactive mismatch and repair: Challenges to the coping infant. Zero to Three, $6,1-6$.

Tronick, E.Z., \& Gianino, A.F. (1986b). The transmission of maternal disturbance to the infant. New Directions for Child Development, 34, 5-11.

Waldo, M.C., Roath, M., Levine, W., \& Freedman, R. (1987) A model program to teach parenting skills to schizophrenic mothers. Hospital and Community Psychiatry, 38(10), $1110-1112$.

Wang, A., \& Goldschmidt, V. (1994). Interviews of psychiatric inpatients about their family situation and young children. Acta Psychiatrica Scandinavia, 90, 459-465.

Waters, B.G.H., \& Marchenko-Bouer, 1. (1980). Psychiatric illness in the adult offspring of bipolar manic-depressives. Journal of Affective Disorders, 2, 119-126.

Webster-Stratton, C., \& Hammond, M. (1988). Matemal depression and its relationship to life stress, perceptions of child behavior problems, parenting behaviors and child conduct problems. Journal of Abnormal Child Psychology. 16, 299-315.

Zahn-Waxler, C., Iannotti, R., Cummings, E., \& Denham, S. (1990). Antecedents of problem behaviors in children of depressed mothers. Development and Psychopathology. 2, 271-29l.

Zlochower, A., \& Cohn, J. (1996) Vocal timing in face-to-face interaction of clinically depressed and nondepressed mothers and their 4-month-old infants. Infant Behavior and Development, 19, 371-374. 